\title{
Relations between terms: a cognitive approach. The interaction between Terminology, Lexicology, Translation Studies and translation practice
}

\author{
Marcel Thelen \\ Maastricht School of Translation and Interpreting - Hogeschool Zuyd
}

This paper discusses two problem areas of Terminology: the word-term distinction and a particular type of terminological relation, viz. the complex or associative relation. Both areas will be discussed in the light of the actual practice of translating and the translator. It will be argued that for the translator to deal with these areas successfully there should be a contribution from basic translation practices and Translation Studies, on the one hand, and from Lexicology, notably TCM ("Two-Cycle Model of Grammar"), on the other.

\section{Introduction}

Terminology is important for non-literary translation. Its principles can guide the translator through translation problems in the direction of an appropriate translation solution. At least, this is what the translator would expect Terminology to do. Practice is different, however. There is still a considerable gap between Terminology and translation, not so much because terminologists do not seem to be concerned with the actual practice of translating, but mainly because Terminology has long held the position that it is an individual discipline that is clearly distinct and distinguishable from Lexicology. With the formulation of Socio-Cognitive Terminology (see Temmerman 1998/2000, 2000, and 2001), however, this situation is changing slightly. As a result, the term-word distinction may have become less pronounced, but is still problematic and seems to need the help of Translation Studies and translation practice (see Thelen 2002). Moreover, whereas Lexicology is capable of handling relations between lexical items in terms of description and formalisation, Terminology still does not seem to perform well, especially in the case of the so-called associative or complex relationships. In this paper, I will demonstrate that basic translation practices and recent developments in Translation Studies can help Terminology with the term-word distinction and that recent developments in Lexicology, notably TCM (or "Two-Cycle Model of Grammar") can help Terminology with the formalisation and description of associative relations. I will argue that both developments and a form of Terminology thus enriched may, in their turn, help translators in their work.

\subsection{Words vs. terms}

For a specialised translator (i.e. one who translates non-literary texts belonging to specialised subject fields), and most clearly for a student of specialised 
translation, it is important to know whether what they come across is a term or a word. If it is a word, they have a certain degree of translation freedom; if it is a term, they are more or less bound to use an equivalent term in their translation. The most treacherous and most difficult are those items that look like ordinary words, but ultimately appear to be terms (see Thelen 2002). Also, from a purely pragmatic point of view, the term-word distinction is certainly important for a translator/student of translation, because this may make a crucial difference as to where to look up an item, i.e. in a general dictionary, a special subject field dictionary or in a terminological vocabulary (see Varantola 1992:124-125).

\subsection{Relations between terms: associative or complex relations}

The term-word distinction is the first step towards a solution of translation problems: it may determine not only what translation procedures translators can/may apply ${ }^{1}$, but also what type(s) of structural relations they may use as heuristic discovery procedures for the selection of the most appropriate candidate target text equivalent from among a number of possible items. It is quite conceivable that terms allow other translation procedures and relations than words. If an item is a word, for example, the translation procedure of recognised translation is less likely to be applicable. Likewise, if an item is a word, other relations may apply than the known terminological relationships (equivalence, generic relation, part-whole relation, and associative relation). If the item in question is a term, then it may be important to know what the difference is between the various terminological relationships, but most importantly, what their underlying principles are, i.e. their identifying templates.

Of all terminological relationships the associative relation is the least logically-based and, therefore, the most difficult to formalise, yet it is the most frequently occurring relationship, that desperately needs clarification and structuring. It simply is the rag-bag type of terminological relationship and, consequently, perhaps the most difficult to grasp. As a result, terminologists may find it rather difficult to formalise for computational purposes.

\section{Terminology vs. Lexicology}

Before we say more about the distinction between words and terms and before a typology of terminological relationships can be given, we must look into the parallel between Terminology and Lexicology.

\subsection{Traditional Terminology vs. Socio-Cognitive Terminology}

Traditional Terminology (e.g. Wüster 1979; Picht \& Draskau 1985; Felber 1984), or Standardisation-Oriented Terminology (for the latter term see 
Temmerman 2000:453), claims that it deals with language for special purposes, and that Lexicology deals with general language, in other words, that there is a strict boundary between language for special purposes and general language, and thus between Terminology and Lexicology. However, a statement like this cannot deny the existence of situations where general language is intentionally used as language for special purposes (terminologisation in terms of Meyer 2000), or where language for special purposes has lost its special character and has become general language (de-terminologisation according to Meyer 2000). In other words, there cannot be a strict boundary between the two; the boundary is a fuzzy ${ }^{2}$ one. Yet, the general view among traditional terminologists seems to be that the boundary is clear-cut and not fuzzy at all. The same seems to be true of the boundaries within Terminology itself, i.e. the boundaries between terms. Thus, whereas Traditional Terminology seems to lack fuzzy boundaries between categories (a principle that has become almost a doctrine in Cognitive Linguistics), Lexicology (conceived of in terms of Cognitive Linguistics) recognises almost "naturally" that there are fuzzy boundaries and explicitly applies them (see e.g. Geeraerts 1986). This view was further elaborated on and advocated by Temmerman (1998/2000, 2000, and 2001) who introduced the notion of Socio-Cognitive Terminology, viz. a conception of Terminology that states that:

1. Socio-Cognitive Terminology starts from units of understanding which more often than not have prototype structure

2. Understanding is a structured event. A unit of understanding has intracategorial and intercategorial structure and it functions in cognitive models

3. Depending on the type of unit of understanding and on the level and type of specialisation of sender and receiver in communication, what is more essential or less essential information for a definition will vary

4. Synonymy and polysemy are functional in the process of understanding and therefore need to be described

5. a) Units of understanding are constantly evolving. The historical periods in their evolution may be more or less essential for the understanding of a unit, b) Cognitive models (e.g. metaphorical ICMs [Idealised Cognitive Models (MT)]) play a role in the development of new ideas which implies that terms are motivated. (Temmerman 1998:351-352)

\subsection{The term-word distinction}

As regards term vs. word, the boundary between the two (and therefore, the difference between the two) is as fuzzy and vague as that between general language and language for special purposes: terms can come to be used as words, and words can become terms. Neither Lexicology nor Terminology (be it Traditional Terminology or Socio-Cognitive Terminology) seem to be able to give strict rules for distinguishing terms from words. Nowhere in the literature on Terminology is the notion of term defined adequately enough so as distinguish terms from words under all circumstances. Most formulations do not go any further than giving a number of possible morphological, ety- 
mological, phonological and/or combinatory distinguishing criteria (e.g. Cabré 1999:81-92), but clearly these are neither sufficient nor adequate. The criteria given seem to be rather static and objectivistic. An exception is perhaps S.D. Shelov (1982), who introduced the notion of "degrees of terminologicality" (referred to in Picht \& Draskau 1985:97-98): the more information is needed to understand a lexical item, the more "terminological" this lexical item is.

\section{Basic translation practices and Translation Studies vs. the term-word distinction}

It would seem that for the term-word distinction, other criteria are needed. These come from translation practice and Translation Studies. Let me begin with translation practice. One of the basic rules translators must follow is that they should not start a translation without first having performed a macro-analysis, i.e. they should collect as much relevant information as possible on such "circumstantial" aspects as author, source, audience, subject matter, style, register, etc. On the basis of this information they can then decide if the text to be translated is likely to contain general language or specialised language, viz. words or terms. These "circumstantial" aspects are referred to in Translation Studies as communicative setting (Pearson 1998) or levels of communication (e.g. Thelen 2002). Pearson (1998:28) states: "With regard to the notion of communicative setting, we suggest that this may be the most important factor in allowing us to decide whether words are being used as terms or words".

Translation Studies also contributes in another way, viz. by means of the notion of textuality (see Neubert \& Shreve 1992:70, and Neubert 2001). Textuality refers to a formalisable property of a text that can be used as a rather objective means for text comparison and is revealed by such characteristics as intentionality (or the presence/absence of an intention/purpose of the (author of a) text), acceptability (or recognisability as a meaningful text), situationality (or the location of a text in a discrete socio-cultural context in a real time and place), informativity (or the degree of informativity/information content of a text), coherence (semantic or propositional cohesion), cohesion (surface cohesion), and intertextuality (a global pattern which the reader compares to pre-existing cognitive templates abstracted from experience). The contribution from translation practice and Translation Studies, therefore, is that item-external factors may play a role in the term-word distinction.

\section{Terminological relations: complex, or associative, relations}

In Terminology, there does not seem to be agreement on the various types of relation that exist between terms. Felber (1984), and Picht \& Draskau (1985), for example, distinguish logical relations, ontological relations and 
other relations, whereas Sager (1990) discerns generic, partitive and complex relations as the most frequent types. Still others, e.g. de V. Cluver (1989), mention associative relationships, generic relationships, and partwhole (partitive) relationships. Next to these relations (which are often called relations between concepts), another group of relations is distinguished in e.g. Picht \& Draskau (1985:98), viz. the group of term-concept relations, such as monosemy, polysemy, synonymy, equivalence, and homonymy. In this paper, however, when I speak about relations between terms, I do not distinguish between relations between concepts and conceptterm relations, and following Sager's classification I will concentrate on the complex or associative relation.

Sager (1990:34) describes (rather than defines) the complex relation as "Concepts are often seen as being inter-related in a complex manner which cannot conveniently be captured by straightforward generic and partitive structures". This description is rather vague and uninformative. It does not reveal anything about the nature of the relation. De V. Cluver (1989) is as uninformative in his definition of the associative relation: "Sense relation between two terms that are not semantically equivalent, but nevertheless exhibit clear semantic relatedness between them. In a thesaurus these terms are marked by the symbol RT (related term)". This definition does not say anything on the specific nature of the semantic relatedness. From the examples Sager (1990:34-35) gives, it is not clear how the particular type of complex relation between two terms is established, e.g.:

\section{FALLOUT \\ COMPUTER TOOL BOX}

\section{Relationships:}

$\begin{array}{lll}\text { cause } & - & \text { effect } \\ \text { process } & - & \text { product } \\ \text { process } & - & \text { instrument } \\ \text { process } & - & \text { patient } \\ \text { object } & - & \text { counteragent } \\ \text { object } & - & \text { material }\end{array}$

\section{Type of relation} is caused by is an instrument for is a container for

\section{NUCLEAR EXPLOSION DATA PROCESSING TOOLS}

$\begin{array}{lll}\text { Examples: } & & \\ \text { explosion } & - & \text { fall-out } \\ \text { weaving } & - & \text { cloth } \\ \text { incision } & - & \text { scalpel } \\ \text { dying } & - & \text { textile } \\ \text { poison } & - & \text { antidote } \\ \text { bridge } & - & \text { iron }\end{array}$

Types of relations and examples according to Sager (1990:34-35)

The question here is how the semantic relatedness in the associative relationship can be captured in a structure and what this structure could be. Formulating the semantic relatedness by saying that form $\mathrm{X}$ is a necessary component in the definition of form Y is not enough ("there is an associative relation between ORNITHOLOGY and BIRD because BIRD is a necessary component of the definition of ORNITHOLOGY"). Such a statement alone is not sufficient to explicitate the semantic nature of the relationship. 
On the basis of the foregoing and in anticipation of the presentation of the basic principles of TCM, a complex or associative relation between terms can roughly be described as follows:

There is a complex or associative relation between two or more terms iff:

1. the structures of the concepts associated with these terms are such that from them one common conceptual structure can be derived on the basis of which the corresponding terms may be grouped together in one or more conceptual fields or sub-fields for which this particular common conceptual structure happens to form the basis; and

2. one term is a necessary part of the definition of the other term, i.e. if one term is used as a conceptual component in the structure of the concept associated with the other term.

Condition (1) clearly relates to meaning, and condition (2) to a combination of form and meaning (i.e. form "re-used" as a component of meaning).

\section{Basic principles of TCM}

TCM stands for "Two-cycle Model" of grammar. It was originally formulated by Alinei (1980), the logical follow-up to Alinei (1974). It was further developed by Thelen $(1987,1991,1992)$. It is a meaning-based linguistic model of grammar which essentially states that words have an underlying conceptual-syntactic structure, which facilitates a motivated and structured organisation and categorisation of unordered sets of words and terms. The associative relationship to be formulated in this paper will be treated from a Cognitive-Semantic perspective.

In TCM, lexical items have concepts associated with them. A concept is considered to be a shortcut for an actual sentence, and thus has a structure similar to that of an actual sentence. The structure of a concept is called a conceptual-syntactic structure with conceptual-syntactic categories such as $S B$ (for "Subject"), $P D$ (for "Predicate") and $O B$ (for "Direct Object"), and the structure of an actual sentence is called syntactic structure with syntactic categories such as $N P$ and VP. Another term for conceptual-syntactic structure is Internalised Sentencel Phrase, and the purely syntactic structure of an actual sentence is called Externalised Sentence/Phrase. In TCM, the grammar consists of two twin cycles: the Lexical Cycle and the Sentence Cycle, the former accommodating Internalised Sentences or Phrases, and the latter Externalised Sentences or Phrases.

Let me give an example. Take the lexical item write. The definition of one of its senses given in Longman (1991) is " $v t$ to form (legible characters, symbols, or words) on a surface, esp. with an instrument". Though in this definition no subject is given, it is implicitly understood to be a human being. In terms of TCM, the Internalised Sentence of the concept associated with this lexical item would be: 
$S B<$ human $>P D<$ form $>O B$ <legible characters, symbols, or words $>$

LOC <on a surface> INSTR <with an instrument>

where: SB = Subject

$\mathrm{PD} \quad=$ Predicate

$\mathrm{OB} \quad=$ Direct Object

LOC = Location

INSTR $=$ Instrument

Internalised Sentence of "to write"

The twin counterpart of the conceptual-syntactic categories SB, PD, OB, LOC, and INSTR in an actual sentence like "Mary wrote her name with a pencil" would be the syntactic categories NP and VP as follows:

$$
\begin{aligned}
\mathrm{NP}^{1}[\text { Mary }] \mathrm{VP}\left(\mathrm{VB}[\text { wrote }] \mathrm{NP}^{2}[\text { her name }] \mathrm{AP}^{1}[\ldots] \mathrm{AP}^{2}[\text { a pencil }]\right. \\
\text { where: } \begin{array}{ll}
\mathrm{NP}^{1}= & \text { Noun Phrase having the function of Subject } \\
\mathrm{VP} & =\quad \text { Verb Phrase } \\
\mathrm{VB} & =\quad \text { Verbal element, corresponding to Predicate } \\
\mathrm{NP}^{2}= & \text { Noun Phrase having the function of Direct Object } \\
\mathrm{AP}^{1}= & \text { Adverbial Phrase, corresponding to LOC } \\
\mathrm{AP}^{2}= & \text { Adverbial Phrase, corresponding to INSTR }
\end{array}
\end{aligned}
$$

The elements occupying the various conceptual-syntactic categories in Internalised Sentences are called conceptual-semantic components or features, and the elements occupying the purely syntactic categories in Externalised Sentences are called lexical items.

What we see here is that the LOC category of the Internalised Sentence is not present in the Externalised Sentence. This means that it is understood but not expressed explicitly. It might have been expressed as “... on a piece of paper".

TCM has other important characteristics, viz. the notions of Exchange of Functions/ Recycling, Taxonomy, Lexical System, Lexical Domain, and Borrowing.

\subsection{Exchange of Functions/Recycling}

The notion of Exchange of Functions/Recycling ${ }^{3}$ refers to the very important principle that lexical items already generated or lexicalised may be used to function as conceptual-semantic components in the generation of other lexical items. This notion is not new (see e.g. Dik 1978), but TCM applies it in a very straightforward and consistent way. 


\subsection{The Taxonomy}

Like all theories or models of lexical semantics, TCM makes use of taxonomies or hierarchies. In TCM taxonomies, the principle of Exchange of Functions plays a crucial role (example taken from Thelen 1999):

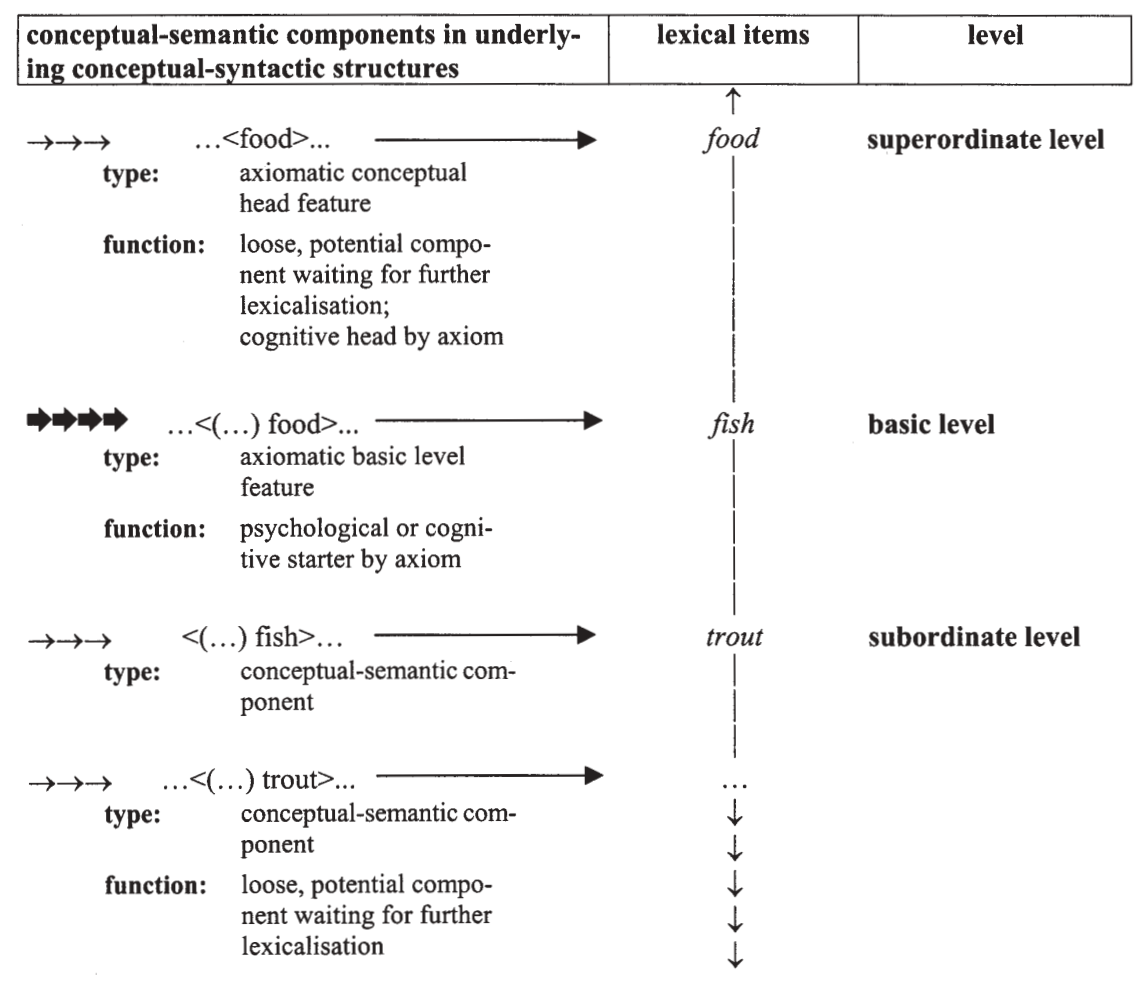

A taxonomy in TCM

\subsection{The Lexical System}

From the Internalised Sentences for the various lexical items a so-called Lexical System may be abstracted, which in its turn is said to group the various lexical items. TCM stipulates that these lexical items belong to one and the same group whose Internalised Sentences are such that at least the conceptual-syntactic categories of SB and PD are "filled" by the same conceptual-semantic components. Of course, one should not limit oneself to one particular definition and/or context of a particular lexical item (term or word) to formulate an Internalised Sentence and use this - together with Internalised Sentences for other lexical items - as the basis for the formulation of a Lexical System. Many definitions and/or contexts for one particular lexical item should be considered so as to be able to compare the various 
Internalised Sentences formulated on their basis and to distil the best common elements (i.e. conceptual-syntactic categories as well as conceptualsemantic components) from this comparison for the formulation of a common Internalised Sentence. In this way many lexical items should be considered for the formulation of the ultimate Lexical System. For more details see e.g. Thelen (1992).

\subsection{The Lexical Domain}

The notion of Lexical Domain refers to a group of lexical items that share among them one conceptual-semantic component in their Internalised Sentences, regardless of which conceptual-syntactic category is occupied by this conceptual-semantic component.

\subsection{Borrowing}

Borrowing means that conceptual-semantic components from a particular taxonomy in one Lexical System can be borrowed for the lexicalisation of lexical items in a taxonomy in another Lexical System. Borrowing functions in this way not only between Lexical Systems, but also between Lexical Domains, and between Lexical Systems and Lexical Domains. Basically, borrowing entails that conceptual-semantic components are exchanged between taxonomies.

\section{TCM applied to complex, or associative, relations}

Let me begin with an example taken from a third-year Terminology paper ${ }^{4}$ by one of my students: tight money. The subject of this paper was economics, especially receipts in international trade. In the Macmillan Dictionary of Modern Economics (1986) she found the following definition: "A monetary policy applied when the supply of credit is restricted and the interest rates are high. The object of such a policy is to reduce the general level of demand, or restrain its growth, in the interests of restraining a rise in prices or improving an adverse balance of payments (or both)".

From this definition the following TCM conceptual-syntactic categories and conceptual-semantic components may be distilled:

SB: not given, but inherent in monetary policy: <government>

PD: <apply>

OB: <monetary policy>

CIRC.: <when the supply of credit is restricted and the interest rates are high $>$

PURPOSE: < to reduce the general level of demand, or restrain its 
growth, in the interests of restraining a rise in prise or improving an adverse balance of payments (or both)>

Conceptual-semantic components for "tight money"

In terms of TCM, this would lead to the following Internalised Phrase (IP) ${ }^{5}$ :

IP: $O B<$ monetary policy $>\{\{W H P D P A S S<$ apply $>S B<$ government>CIRC. <when the supply of credit is restricted and the interest rates are high> PURPOSE < to reduce the general level of demand, or restrain its growth, in the interests of restraining a rise in prices or improving an adverse balance of payments (or both)>\}\}

\section{Internalised Phrase for "tight money"}

From this IP, the following Lexical System (LS) may be derived:

LS: $S B<$ government $>P D<$ apply> $O B<$ monetary policy> $C I R C$. $<$ when the supply of credit is restricted and the interest rates are high> PURPOSE < to reduce the general level of demand, or restrain its growth, in the interests of restraining a rise in prices or improving an adverse balance of payments (or both)>

\section{A Lexical System in TCM}

In this LS, a few things have been left implicit. It is, of course, obvious that "demand" in "general level of demand" should be understood as "demand of credit" and "growth" as "growth of the demand of credit". What will eventually be included in conceptual-syntactic structures as conceptual-semantic components depends on the degree of abstraction from the actual formulations of definitions.

With a view to TCM's principle that, in order to be able to establish Lexical Systems that are as complete and accurate as possible, one would have to turn to other definitions as well (which the student had done, but not accounted for in her paper), I looked up tight money in e.g. the Longman Dictionary of Business English (1982). Under tight money, I was referred to dear money, and from there I arrived at dear money policy, which was the appropriate entry (note by the way, that in the Macmillan Dictionary of Modern Economics (1986) policy is "included" in tight money, whereas in the Longman Dictionary of Business English (1982) it is "excluded", i.e. has to be expressed next to it). It was defined as: ".. in Britain, when the government, through the Bank of England, decides to hold back spending, it makes money dearer to borrow by raising the interest rates, esp. the Bank of England minimum lending rate".

It is clear, of course, that this policy is not restricted to Britain only; therefore, "in Britain" is rather strange in this definition. For the same reason, "the Bank of England" is better replaced by its hyperonym central bank (leaving implicit that it is the central bank of the country in question; this might be made explicit in the IP and LS by means of the addition of the coun- 
try). The part "through the Bank of England" may be incorporated in both IP and LS as MEDIUM <the central bank of the country>. For the rest, this definition does not add anything new.

In principle, associative or complex relations may exist or be established between the term in question, tight money, and all the conceptualsemantic components in the conceptual-syntactic structure underlying the term, thus its IP and eventually its LS. It should be recalled that these conceptual-semantic components function as terms themselves elsewhere. The conceptual-syntactic categories occupied by these conceptual-semantic components may be taken to indicate the nature of the various complex, or associative, relations. Thus, there is a complex, or associative, relation between the following terms:

(1) tight money (a)

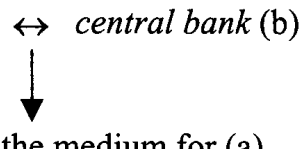

NATURE: (b) is the medium for (a)

(2)

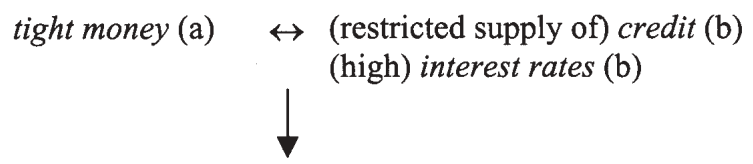

NATURE: (b) is the circumstance for (a)

(3)

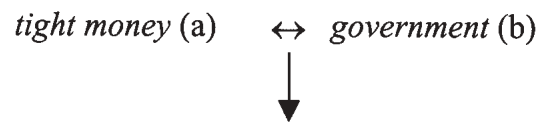

NATURE: (b) is the initiator of (a)

(4)

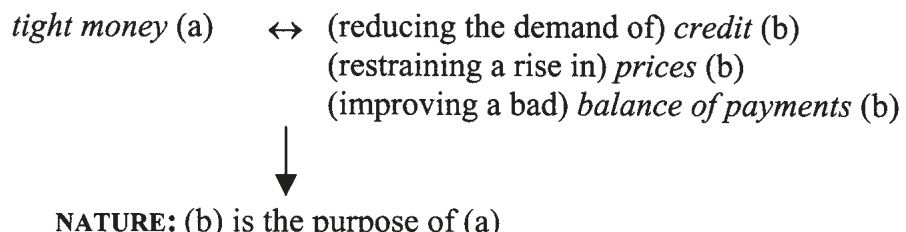

In terms of TCM, a complex, or associative, relation between terms can now be defined as follows. There is a complex, or associative, relation between any two terms iff:

1. the underlying conceptual-syntactic structures of these terms (thus, their Internalised Phrases) together with their conceptual-semantic content are thus that from them one common abstracted conceptual-syntactic structure (thus, a Lexical System) can be derived; and

2. one of the terms functions as a conceptual-semantic component in any of the conceptual-syntactic categories of the conceptual-syntactic structure underlying the other term. 
Let me give another example. When one looks up monetary policy in a dictionary, e.g. the Longman Dictionary of Business English (1982), one finds "FIN. the control, by the government, of a country's currency and its system for lending and borrowing money, esp. through the supply of money". This definition gives rise to the formulation of a Lexical System like:

$S B<$ government $>P D<$ control $>O B<$ a country's currency and its system for lending and borrowing money> MEANS <the supply of money>

In this definition, we see the elements government and currency. Because of their presence in this definition of monetary policy, it is possible to establish associative relations between these elements and monetary policy:

(5)

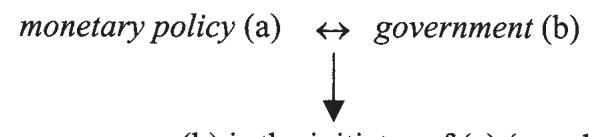

NATURE: (b) is the initiator of (a) (see above)

(6)

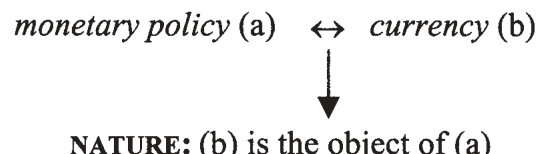

Apart from this, the elements of government and currency, but also other elements such as e.g. money, specify the Lexical Domain to which monetary policy can be said to belong: it is part of the Lexical Domains of <government>, <currency>, and <money>. Also these relations, i.e. the relation between a term and its Lexical Domain, might be called a type of associative relation.

\section{Advantages of the TCM approach}

The first advantage of the TCM approach to complex, or associative, relations between terms that presents itself naturally is that it allows for a more precise definition of this type of terminological relation. This is, of course, extremely important in an educational setting. It is after all rather difficult to teach students of translation what a complex relation is and how and when it should be established between terms if it is ill-defined. In addition to this, the TCM definition of the notion of complex relation can be applied in a rather straightforward and, what is more, consistent way. This is not just important from a user perspective, it is also crucial from the perspective of the data to be classified: they will be treated in a consistent way. And it is here that TCM may be useful to computerised Terminology work.

Another, theoretically more important, advantage of TCM is that Lexical Systems make the grouping of terms and the description of systems of concepts both easier and more consistent. The TCM description of a sys- 
tem of concepts will be both more detailed, and more powerful and comprehensive. By means of the notion of Lexical System not only terms belonging to one particular part of speech can be related to one another in a structured way, but also terms belonging to different parts of speech. And by means of Lexical Domains even larger groups of terms may be established. TCM can thus make a strong contribution to thesaurus making.

Now suppose that for a particular terminological subject field all the terms have been classified in line with the principles of TCM, viz. by means of Taxonomies, Lexical Systems and Lexical Domains. On the basis of this classification, it would be possible for a terminologist to decide whether a given term falls within or outside this subject field. And this could be very helpful for computerised Terminology. Also for translation this might be relevant. In addition to this, a specialist bilingual lexicon organised by these principles may be very helpful for translators. It may help them establish the appropriate translation equivalent of a given form. This would, of course, be a welcome help in cases of translation problems (e.g. wrong use of terms in one of the languages in the translation pair, neologisms, etc.). A similar situation would hold for a bilingual lexicon covering general language.

Another advantage would be that the TCM framework could provide a good basis for the validation of equivalents for terms and the validation of definitions. It might also be helpful in the standardisation of terms.

Last but not least, the notion of Lexical System could function as a means to impose a limit on the range of terms to be captured by (a) particular associative relation(s) and thus to prevent associations which are too loose or indirect. Let me give an example taken from a third-year Terminology paper by one of my students. The student in question claimed there was an associative relation between the following terms:

\author{
period of a loan \\ bank credit \\ commercial credit (also called trade credit)
}

She formulated the nature of this claimed associative relation as follows: "The period of a loan determines, together with the size and financial position of a company, what type of credit the company will choose. If the period is short or average, more often a commercial credit will be chosen instead of a bank credit". Apart from the question of whether period of a loan is a term, this claimed associative relation is clearly a bit far-fetched or too indirect. This could never be captured by a Lexical System.

\title{
8. Epilogue
}

Though a lot of research has still to be done on TCM and though it should first be applied to large numbers of data before final claims can be made about its usefulness and applicability, the data so far look promising. What goes for associative relations between terms seems to go for the other types 
of relation as well, viz. generic relations and part-whole relations. As such, TCM seems to be able to impose structure on Terminology and Lexicology and should deserve serious attention.

TCM also seems to make the question of whether Lexicology and Terminology are independent disciplines rather superfluous, since it may be applied to both with the same results. What is more, TCM not only seems to be capable of bridging the gap between Terminology and Lexicology because of its cognitive approach to relations between terms, on the one hand, and of lexical items, on the other; it also constitutes a rich contribution to the actual practice of translating, in particular the translation of figurative language (see Thelen 1996). In this publication, it was argued that because the structures underlying words are in principle similar to those of actual sentences, Lexical Systems (in which conceptual content is structured) can serve as a ground of comparison between words and sentences; deviations in the conceptual pattern of a sentence can then be traced by comparing its conceptual content with that of the conceptual structure underlying the problem word in the sentence. For these reasons too, TCM deserves serious attention.

Summarising, for the term-word distinction Translation Studies alone is not sufficient; it should be supported by translation practice, and in this joint contribution one may benefit from the other. However, despite this joint effort, the boundary between word and term will remain fuzzy. What is clear is that this fuzziness cannot be accounted for by Traditional Terminology; Temmerman's Socio-Cognitive Terminology is a better candidate, though it merely seems to recognise the existence of this fuzziness but does not give a prototypical definition of a term $v s$ a word. Of all these contributors translation practice seems to be the most succesful. In other words, it will still be the translator who has to take the ultimate decision. The translator may try to find support from Corpus Linguistics and specialised corpora, or work with a translation memory, but these do not solve the term-word problem; they only give equivalents and are more useful for consistency only; they cannot assist in any way when items come up that are not included in their databases. The same seems to be true of machine translation.

Though TCM does not appear to be helpful for the term-word distinction, it not only contributes, by its very nature, to Linguistics and Lexicology, it can be useful for other areas as well, notably translation practice, Terminology and Translation Studies. TCM offers a framework for a structural description of the semantic relatedness in associative relations between terms; it is in particular the Lexical System and the Lexical Domain that are important in this respect. In this way, TCM (thus Lexicology) contributes to Terminology. TCM's principles can also be useful for translation practice, e.g. the translation of figurative language. Finally, TCM's Lexical Systems and Lexical Domains may also constitute a useful contribution to Translation Studies, in particular machine translation; here, the Lexical System and the Lexical Domain could be useful for the disambiguation of polysemic items and thus complement syntactic parsing. Likewise, both Lexical Systems and Lexical Domains may be relevant to Corpus Linguistics. 


\section{Bibliography}

Alinei, M. (1974). La Struttura del Lessico. Bologna: il Mulino.

Alinei, M. (1980). "Lexical Grammar and Sentence Grammar. A Two-cycle Model." Quaderni di Semantica. An International Journal of Theoretical and Applied Semantics 198(1). Bologna: il Mulino, 33-95.

Cabré, M. T. (1999). Terminology. Theory, methods and applications. Amsterdam/ Philadelphia: John Benjamins Publishing Company.

de V. Cluver, A. D. (1989). Dictionary of Terminography. Pretoria (South Africa): Human Sciences Research Council

Collins English Dictionary (1994). Updated edition. (Ed. J. M. Sinclair) Glasgow: HarperCollins.

Dik, S. (1978). Stepwise Lexical Decomposition. Lisse: Peter de Ridder Press.

Felber, H. (1984). Terminology Manual. PGI-84/WS/21. Paris: Unesco, Infoterm.

Geeraerts, D. (1986). Woordbetekenis. Een overzicht van de lexicale semantiek. Leuven/Amersfoort: Uitgeverij ACCO.

Heid, U et al. (eds) (2000). EURALEX 2000. Proceedings of the Ninth EURALEX International Congress, Stuttgart, Germany, August 8th - 12th, 2000, Volume I. Stuttgart: Universität Stuttgart, Institut für Maschinelle Sprachverarbeitung.

Lakoff, G. (1982). "Categories and Cognitive Models." L.A.U.T. (Linguistic Agency University of Trier). Series A, Paper No. 96.

Lewandowska-Tomaszczyk, B. \& M. Thelen (eds) (1992). Translation and Meaning. Part 2. Proceedings of the 1990 Maastricht-Lódz' Duo Colloquium on "Translation and Meaning". Held in Lódź, Poland, 20-22 September 1990. Maastricht: Rijkshogeschool Maastricht, Faculty of Translation and Interpreting.

Lewandowska-Tomaszczyk, B. \& M. Thelen (eds) (1996). Translation and Meaning. Part 4. Proceedings of the 2nd International Maastricht-Lódź Duo Colloquium on "Translation and Meaning". Held in Lódź, Poland, 22-24 September 1995. Maastricht: Hogeschool Maastricht, School of Translation and Interpreting.

Lewandowska-Tomaszczyk, B. \& M. Thelen (eds) (2002). Translation and Meaning. Part 6. Proceedings of the Lódź Session of the 3rd International MaastrichtLódź Duo Colloquium on "Translation and Meaning”, Held in Lódź, Poland, 22 - 24 September 2000. Maastricht: Hogeschool Zuyd, Maastricht School of Translation and Interpreting.

Longman Dictionary of Business English (1982). (Ed. J. Adam) Burnt Mill, Harlow/Essex: Longman Group Limited.

Longman Dictionary of the English Language (1991). Major new edition. (Ed. S. Engineer \& H. Gay) Burnt Mill, Harlow/Essex: Longman Group Limited.

Macmillan Dictionary of Modern Economics (1986). Third edition. (Ed. D. Pierce) London: The Macmillan Press.

Meyer, I. (2000). "Computer Words in Our Everyday Lives: How are they interesting for terminography and lexicography?" U. Heid et al. (eds) (2000), 39-58.

Neubert, A. \& G. Shreve (1992). Translation as Text. Kent, Ohio / London, England: The Kent State University Press.

Neubert, A. (2001). "Translation in a textual context: a new appraisal." M. Thelen \& B. Lewandowska-Tomaszczyk (eds) (2001), 55-72.

Newmark, P. (1988). A Textbook of Translation. New York/London, etc.: Prentice Hall.

Pearson, J. (1998). Terms in Context. Amsterdam/Philadelphia: John Benjamins Publishing Company. 
Rosch, E. (1978). “Principles of Categorisation.” E. Rosch \& B. Lloyd (eds) (1978). Cognition and Categorisation. Hillsdale NJ: Lawrence Erlbaum Associates, Publishers, 27-48.

Picht, H. \& J. Draskau (1985). Terminology: an introduction. Guildford/Surrey: The University of Surrey, Department of Linguistic and International Studies.

Sager, J. C. (1990). A Practical Course in Terminology Processing. Amsterdam: John Benjamins Publishing Company.

Temmerman, R. (1998). Terminology beyond Standardisation. Language and Categorisation in the Life Sciences. $\mathrm{PhD}$ thesis. Leuven: Catholic University of Leuven. Also published as Temmerman, R. (2000). Towards New Ways of Terminology Description. The sociocognitive approach. Amsterdam/Philadelphia: John Benjamins Publishing Company.

Temmerman, R. (2000). "Training Terminographers: the Sociocognitive Approach." U. Heid et al. (eds) (2000), 453-460.

Temmerman, R. (2001). "Metaphors the Life Sciences Live By." M. Thelen \& B. Lewandowska-Tomaszczyk (eds) (2001), 43-52.

Thelen, M. (1987). "TCM: A Two-Cycle Model of Grammar. Some extensions of Alinei's original 1980 formulation." R. Crespo, B. Dotson Smith \& H. Schultink (eds) (1987). Aspects of Language. Studies in Honour of Mario Alinei, Volume II. Amsterdam: Rodopi, 493-507.

Thelen, M. (1991). "Categorization and Translation." M. Larson (ed.) (1991). Translation: Theory and Practice. Tension and Interdependence. American Translators Association, ATA, Scholarly Monograph Series, Volume V. New York: State University of New York at Binghamton (SUNY), 71-86.

Thelen, M. (1992). "Stasis and Dynamics of Meaning. The Lexicon in a Two-Cycle Model of Grammar." B. Lewandowska-Tomaszczyk \& M. Thelen (eds) (1992), 111-127.

Thelen, M. (1994). "Terminology training for translators.” I. Oubine et al. (eds) (1994). Translation \& Text Linguistics. Moscow: Joint publication of the Russian Center for Translations (Moscow, Russia), and the Department of Russian, Maastricht School of Translation and Interpreting, Hogeschool Maastricht (Maastricht, The Netherlands), 36-53.

Thelen, M. (1996). "Translating figurative language: towards a framework for the interpretation of the image behind figurative language." B. LewandowskaTomaszczyk \& M. Thelen (eds) (1996), 333-353.

Thelen, M. (1999). "Prototypes and the Structure of the Lexicon." Zeitschrift für Anglistik und Amerikanistik. A Quarterly of languages, Literature and Culture (ZAA) XLVII (3). Tübingen: Stauffenburg Verlag, 195-209.

Thelen, M. \& B. Lewandowska-Tomaszczyk (eds) (2001). Translation and Meaning. Part 5. Proceedings of the Maastricht Session of the 3rd International Maastricht-Lódź Duo Colloquium on "Translation and Meaning". Held in Maastricht, The Netherlands, 26 - 29 April 2000. Maastricht: Hogeschool Zuyd, Maastricht School of Translation and Interpreting.

Thelen, M. (2002). "Translation Studies in the year 2000: the state of the art. Terminology in theory and practice." B. Lewandowska-Tomaszczyk \& M. Thelen (eds) (2002), 21-39.

Tommola, H. et al. (eds) (1992). EURALEX '92. Proceedings, Part I. Papers submitted to the 5th EURALEX International Congress on Lexicography in Tampere, Finland. Studia Translatologia, Publications of the Department of Translation Studies, University of Tampere, Finland, ser. A vol. 2. Tampere: Tampereen Yliopisto, 159-172

Varantola, K. (1992). "Words, terms and translators." H. Tommola et al. (eds) (1992), 121-128. 
Wüster, E. (1979). Einführung in die Allgemeine Terminologielehre und terminologische Lexikographie, 2 Teile (General Theory of Terminology and Terminological Lexicography. An Introduction. 2 parts). Vienna/New York: Springer.

\footnotetext{
${ }^{1}$ The translation procedures that I have in mind are those described by Newmark (1988), viz. transference, naturalisation, cultural equivalent, functional equivalent, descriptive equivalent, synonymy, through-translation, shift or transposition, modulation, recognised translation, translation label, compensation, componential analysis, reduction/expansion, paraphrase, equivalence, adaptation, couplets, notes, additions, and glosses.

${ }^{2}$ The notion of fuzzy boundaries plays an important role in the theory of natural categorisation and the model of prototypes (see e.g. Lakoff 1982 and Rosch 1978).

${ }^{3}$ There is a slight difference between Exchange of Functions and Recycling, but I will not go into this here. For more information, see e.g. Thelen (1992).

${ }^{4}$ For a detailed description of the terminology programme at the Maastricht School of Translation and Interpreting of Hogeschool Zuyd, see Thelen (1994). The curriculum described there was reorganised drastically, however, shortly after the publication of this paper.

${ }^{5}$ The symbols $\{\{\}\}$ are a new representation of the old symbol of $/$ I, which indicates that the items in between can be "recovered", i.e. occur, in Externalised Sentences. This change of symbols has a purely practical reason.
} 